\title{
The progression in atrial fibrillation patients with COPD: a systematic review and meta-analysis
}

\author{
Xiaoying Chen ${ }^{1, *}$, Meiling Lin ${ }^{1,2, *}$ and Wei Wang ${ }^{1}$ \\ ${ }^{1}$ Department of Cardiology, The Second Affiliate Hospital of Shantou University Medical College, Guangdong, 515000, China \\ ${ }^{2}$ Department of Cardiology, The First Affiliate Hospital of Shantou University Medical College, Guangdong, 515000, China \\ "These authors contributed equally to this work
}

Correspondence to: Wei Wang, email: stwangwei@126.com

Keywords: COPD, atrial fibrillation, progression, recurrence, meta-analysis

Received: July 28, $2017 \quad$ Accepted: September 22, $2017 \quad$ Published: October 26, 2017

Copyright: Chen et al. This is an open-access article distributed under the terms of the Creative Commons Attribution License 3.0 (CC BY 3.0), which permits unrestricted use, distribution, and reproduction in any medium, provided the original author and source are credited.

\section{ABSTRACT}

Aim: Chronic Obstructive Pulmonary Disease (COPD) and atrial fibrillation (AF) share pathophysiological links, as supported by the high prevalence of AF within COPD patients. AF progression and recurrence can increase the risks of mortality, morbidity and adverse cardiovascular events. The present systematic review and meta-analysis aims to assess the risk for AF progression and recurrence for COPD patients, to further demonstrate the risk of COPD in AF patients.

Methods and Results: A systematic review was conducted in MEDLINE / PubMed and Cochrane Library and Embase, Web of science. Prospective studies including AF patients with COPD were screened and included if matching inclusion and exclusion criteria. 7 studies were included, adding up to 10761 AF patients (1556 with AF and COPD, 9205 without COPD). Mean age from each study ranged from 51 to 81 years, and $57.2 \%$ were male. Hypertension accounted for $75.5 \%$ of the population, and $\mathbf{2 0 . 7 \%}$ had the comorbidity of diabetes mellitus. The pool analysis showed that COPD could promote AF progression ( $\left.O R=1.90 ; 95 \% C I, 1.34-2.68, I^{2}=77 \%, p=0.0003\right)$. For subgroup analysis, we found that COPD could increase the risk of AF recurrence $\left(O R=2.35 ; 95 \% C I, 1.86-2.97, I^{2}=0 \%, p=0.39\right)$. Besides, in the younger group, at the median age of 64 , COPD was still a risk factor for AF progression (OR $=2.22$; $\left.95 \% \mathrm{CI}, 1.80-2.74, \mathrm{I}^{2}=0 \%, p=0.69\right)$.

Conclusions: COPD is an independent risk for AF progression and recurrence, COPD patients with AF carry a worse prognosis than those in sinus rhythm (SR).

\section{INTRODUCTION}

Atrial fibrillation (AF) is the most common form of chronic arrhythmia, with increasing health care burden and the mainly complications of atrial fibrillation are stroke and heart failure. Various studies had demonstrated that AF progression from the paroxysmal atrial fibrillation (PAF) to more sustained forms, and recurrence could increase morbidity and mortality. AF patients with progression have more adverse cardiovascular events and are more often admitted in the hospital [1]. The higher HATCH (hypertension, age $>75$ years, previous transient ischemic attack or stroke chronic obstructive pulmonary disease, heart failure) scores correlate with higher occurrence of AF and a high risk for stroke, which can be used as a selection criteria for intensified Electrocardiograph monitoring [2].

Chronic obstructive pulmonary disease (COPD) is a major public health problem and is characterized by non-reversible airflow limitation. COPD is not only an independent predictor for major adverse cardiac events but also a predictor of AF incidence [3,4]. The rate of AF incident was inversely associated with forced expiratory volume in one second (FEV1). AF prevalence was higher in severe airflow obstruction subject than those with mild or moderate airflow obstruction $[5,6]$. Moreover, the risk of AF hospitalization was higher among the lower FEV1, especially for FEV1 < 60\% [7]. Previous Studies have 
reported that the major cause of deaths in COPD patients is cardiovascular diseases (CVD) rather than respiratory failure and it is more likely to develop acute coronary syndrome and heart failure. Furthermore, COPD contributes most to the increased all-cause mortality of AF [8].

Various mechanisms about the association between AF and COPD had been widely explored. Oxidative stress and chronic systemic inflammation play vital roles in the pathology of COPD, resulting in atrial myocyte breakdown and fibrosis, and as a consequence progress to AF initiation and maintenance. Glycogen accumulation and atrial fibrosis are proved be risk factors for AF progression in animal models [9]. In the hypoxia condition among the COPD patients, matrix metalloproteinases expression increase which is a important molecular for the regulation of atrial structural remodeling [10]. Hypoxia can cause the constriction of pulmonary arteriolar gradually resulting in the pulmonary hypertension. Higher $\mathrm{PaCO} 2$ values and higher pulmonary artery systolic pressure (PASP) value significantly raise the AF prevalence [11]. Furthermore, low potassium is one of most common electrolyte disturbances in COPD, which might be caused by the use of corticosteroids or beta-blockers. The serum potassium level can influence the cell membrane potential. Low serum potassium increases the $\mathrm{p}$-wave duration which is also a predictor for the incidence of AF [12].

Pulmonary hypertension can contribute to right atrial (RA) hemodynamic overloading or stretching, resulting in the prevalence of non-pulmonary vein (PV) foci in the COPD patients [9]. Commonly, most PAF originate from the pulmonary veins (PVs).There are still some other originations in the non-PV foci such as the superior vena cava (SVC), left atrial free wall (LAFW), crista terminalis (CT), coronary sinus ostium, ligament of Marshall, left atrial appendage, and interatrial septum which have been proved to be a risk factor for AF progression and recurrence. Among these patients the non-PV triggers could not be incompletely eliminated. Moreover, the RA conduction time is prolonged with COPD and the prevalence of typical atrial flutter recurrence increases positively with the severity of COPD, regardless of effective therapies [13].

Although many traditional factors that cause heart structural remodeling such as hypertension, age, heart failure, diabetes can promote AF progression and recurrence, there is few data concerning the influence of COPD on progression and recurrence in all kinds of AF patients [14].

A wide range of methods including catheter ablation, pharmacological cardioversion, electrical cardioversion are used for the maintenance of sinus rhythm in AF patients. The AF recurrence and progression rates are still high causing a heavy economic burden. Therefore, the present systematic review and meta-analysis aims to investigate the role of predictor that COPD plays for $\mathrm{AF}$.

\section{MATERIALS AND METHODS}

\section{Search strategy and criteria}

Firstly, we searched MEDLINE/PubMed, EMBASE and Cochrane databases and Web of Science. The following MeSH, full text and keyword terms: "atrial fibrillation" AND ("COPD" OR "chronic obstructive pulmonary disease" OR "Pulmonary Disease, Chronic Obstructive") were used to identify all the published articles in English. We excluded the trials published solely in abstract form because the results could not be fully analyzed.

\section{Data extraction}

Two blinded reviewers (Xiaoying Chen and Meiling Lin) first screened independently the citations. The specific inclusion criteria were: (1) human studies, (2) the investigated patients are AF patients which was not developed after the CABG, (3) included the outcome of atrial progression and recurrence, (4) the mean follow-up of at least 6 months, (5) progression was defined as change from paroxysmal or persistent AF to a more sustained form, (6) recurrences were defined as episodes of AF or atypical atrial flutter or atrial tachycardia lasting at least 30 s detected during follow-up at least after 6 months. Exclusion criteria: (1) non-human studies, (2) studies including patients undergoing CABG atrial fibrillation, (3) valvar atrial fibrillation.

\section{Statistical analysis}

Since none of the included studies was random control trail, we assessed risk of bias using the Newcastle-Ottawa scale. The pooled Odds ratio and $95 \%$ confidence intervals were calculated using the Mantel-Haenszel method. A fixed-effect model was used if the trials were similar, and a random-effects model was used if they varied. The numbers with progression or recurrence were calculated. Plot analysis was used to evaluate potential publication bias, and Cochran $Q^{2}$ tests and $\mathrm{I}^{2}$ to investigate heterogeneity.

\section{RESULTS}

\section{Search results}

The searching strategies in different database identified 962 abstracts (538 in PubMed/MEDLINE, 161 in Web of Science 173 in EMBASE, 90 In Cochrane library. Among them 895 were excluded according to the application of exclusion and inclusion criteria. 67 of them were selected and full text was read by two blinded authors. Among them, 2 were case reports and 3 were without data. 49 were excluded because of incomplete baseline, follow-up characteristics, or without the outcome of progression or recurrence. 4 were excluded because of 
reporting duplicate data and 2 because it was a case report. Following this selection approach, 7 trials were identified and finally 7 studies were included in the meta-analysis (Figure 1).

\section{Baseline patient characteristics}

Our literature search identified $7 \quad$ studies investigating the potential association between COPD and AF recurrence and progression despite of different cardioversion. A total of 10761 patients with AF were finally included from 7 studies.(1556 with AF and COPD, 9205 without COPD). Based on the 6 studies reporting this detail, 63.9\% were paroxysmal AF, $22.8 \%$ persistent $\mathrm{AF}$ patients, $6.7 \%$ long-standing persistent $\mathrm{AF}$ and $5 \%$ first detected AF. Baseline characteristics are shown in Table 1 and Table 2. Mean age from each study ranged from 51 to 81 years, and $57.2 \%$ were male. Hypertension accounted for $75.5 \%$ of the population. And $20.7 \%$ had the comorbidity of diabetes mellitus (DM). The mean left atrial diameter was $43.3 \mathrm{~mm}$, and mean BMI was $27.4 \mathrm{~kg} / \mathrm{m}^{2}$. 4 studies provided specific therapy [13, 15-17]. Among them, 30.2\% were treated with electrical cardioversion, $45.7 \%$ with antiarrhythmic drugs, and $24.4 \%$ with catheter ablation. As all the studies which were included in this analysis were prospective studies, the Newcastle Ottawa Scale (NOS) was used to assess the methodological quality of the studies. NOS assessment involved a minimum number of zero to a maximum number of 8 depending on the quality of the study being assessed. The results have been listed in Table 3 .

\section{AF recurrence and progression associated with COPD}

As listed in Figure 2, the pool analysis showed that COPD could promote AF progression $(\mathrm{OR}=1.90 ; 95 \% \mathrm{CI}$, $\left.1.34-2.68, \mathrm{I}^{2}=77 \%, p=0.0003\right)$. For subgroup analysis (Figure 3), we also found COPD could increase the risk of AF recurrence $\left(\mathrm{OR}=2.35 ; 95 \% \mathrm{CI}, 1.86-2.97, \mathrm{I}^{2}=0 \%\right.$, $p=0.39)$. Among all the included studies, in the younger ages, at the median age of 64, COPD was still a risk factor for $\mathrm{AF}$ progression $\left(\mathrm{OR}=2.22 ; 95 \% \mathrm{CI}, 1.80-2.74, \mathrm{I}^{2}=0 \%\right.$, $p=0.69)$. Analysis of publication bias was conducted. The funnel plots showed a low to moderate risk of publication bias across the studies based on a visual analysis (Figure 4).

\section{DISCUSSION}

COPD had been demonstrated increasing the risk of cardiac arrhythmia, especially for AF. AF patients with COPD often present more comorbid diseases, and at a higher risk of complications [18]. Among all the present studies concluded, the majority of classified deaths of AF are cardiovascular diseases, whereas non-hemorrhagic stroke or systemic embolism constitute a small part. A 12-year follow-up study had proved that AF progression could increase hospital admissions and major adverse cardiovascular events [19].

Besides, anticoagulation therapy can improve survival in these patients, whether new oral anticoagulation or vitamins $\mathrm{k}$ antagonist [20]. Despite the high prescription of oral anticoagulation (OAC), 1-year mortality and morbidity remain high in AF patients, particularly from heart failure and hospitalizations [21]. Moreover, anticoagulation treatment is inadequate in patients with AF and COPD [22]. It had been proved that COPD, cancer and chronic heart failure (CHF) were each associated with over $20 \%$ increased risk of OAC treatment discontinuation $[20,23]$.

COPD patients showed a higher trend to concomitant with structural heart disease. Our data conformed the positive association between AF progression and high mortality and morbidity [24].

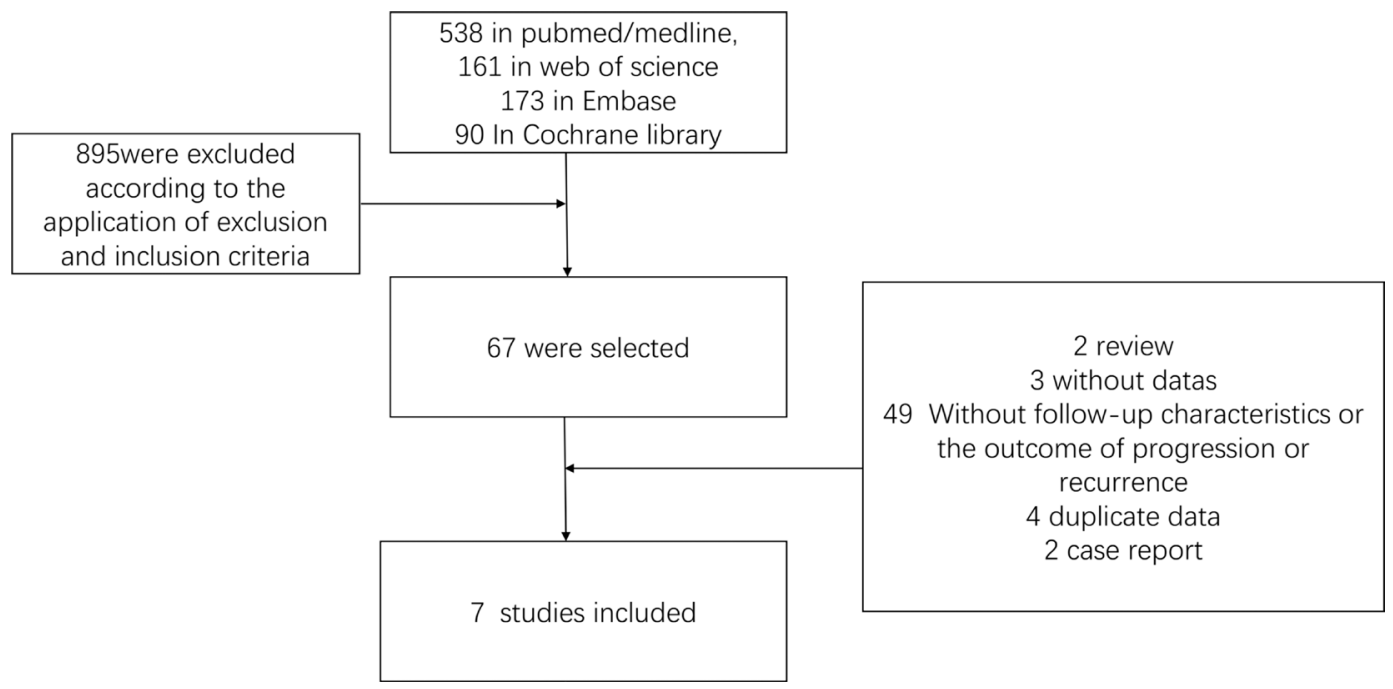

Figure 1: Search criteria and flow graph of the studies screened and included in this meta-analysis. 
Table 1: First author, publication date, population, and main characteristics of the included studies

\begin{tabular}{lclccccccc}
\hline Author & year & study design & $\begin{array}{c}\text { Study } \\
\text { population }\end{array}$ & $\begin{array}{c}\text { Follow-up } \\
\text { (months) }\end{array}$ & $\begin{array}{c}\text { Number of } \\
\text { patients }\end{array}$ & $\begin{array}{c}\text { Mean age } \\
\text { (years) }\end{array}$ & Male & Hypertension & DM \\
\hline Pisters, Ron [15] & 2012 & prospective study & 1801 & 12 & 1801 & 64.1 & 1063 & 1149 \\
Okcun, B. [16] & 2002 & prospective study & 173 & 6 & 110 & $69 \pm 9$ & 56 & 70 & 304 \\
Hayashi, Takekuni [13] & 2013 & prospective study & 181 & $>6$ & 68 & 64.5 & 54 & N/A & N/A \\
Gu, J. [17] & 2013 & prospective study & 550 & $31.4 \pm 4.8$ & 550 & 64.2 & 326 & 290 & 55 \\
de Vos, C. B. [19] & 2010 & prospective study & 1219 & 12 & 1219 & $64 \pm 13$ & 695 & 752 & 182 \\
Holmqvist, F. [29] & 2015 & prospective study & 6235 & 6 & 6235 & $74(65-81)$ & 3554 & 5113 & 1746 \\
Vidal-Perez, R. [24] & 2013 & prospective study & 788 & $33.6 \pm 8.4$ & 788 & $74.8 \pm 9.2$ & 413 & 595 & 192 \\
\hline
\end{tabular}

DM. Diabetes Mellitus; N/A, no available.

Table 2: Baseline characteristics of study population included

\begin{tabular}{|c|c|c|c|c|c|c|c|c|c|c|c|}
\hline Author & year & $\begin{array}{c}\text { Mean AF duration } \\
\text { (months) }\end{array}$ & Paroxysmal & persistent & $\begin{array}{c}\text { long- } \\
\text { standing }\end{array}$ & $\begin{array}{c}\text { First } \\
\text { detected }\end{array}$ & $\begin{array}{c}\text { BMI } \\
\left(\mathrm{kg} / \mathrm{m}^{2}\right)\end{array}$ & $\begin{array}{c}\text { Left atrial } \\
\text { diameter } \\
(\mathrm{mm})\end{array}$ & ECV & Drug & $\begin{array}{l}\text { Catheter } \\
\text { ablation }\end{array}$ \\
\hline Pisters, Ron & 2012 & N/A & 631 & 653 & no & 493 & 27.8 & 44.2 & 712 & 1098 & no \\
\hline Okcun, B. & 2002 & $89.1 \pm 75.3$ & N/A & N/A & N/A & N/A & N/A & N/A & 52 & 58 & no \\
\hline Hayashi, Takekuni & 2013 & $44.4 \pm 56.3$ & 36 & 24 & 8 & no & N/A & $40.0 \pm 7.4$ & no & no & 68 \\
\hline $\mathrm{Gu}, \mathrm{J}$. & 2013 & $59.1 \pm 13.1$ & 191 & 189 & 170 & no & $24 \pm 2.5$ & $46.2 \pm 3.2$ & no & no & 550 \\
\hline de Vos, C. B. & 2010 & N/A & 1054 & no & no & 165 & $27 \pm 4$ & $43 \pm 8$ & $\mathrm{~N} / \mathrm{A}$ & N/A & N/A \\
\hline Holmqvist, F. & 2015 & $42(18-85)$ & 4739 & 1496 & no & no & $29(25-34)$ & $43(38-48)$ & $\mathrm{N} / \mathrm{A}$ & $\mathrm{N} / \mathrm{A}$ & $\mathrm{N} / \mathrm{A}$ \\
\hline Vidal-Perez, R. & 2013 & $73.2 \pm 61.2$ & 106 & 55 & 529 & 88 & $30.1 \pm 4.8$ & N/A & N/A & N/A & N/A \\
\hline
\end{tabular}

N/A, no available; $\mathrm{AF}$, atrial fibrillation; BMI, body mass index; ECV electrical cardioversion.

Table 3: The Newcastle-Ottawa Scale (NOS) for assessing the quality of the studies

\begin{tabular}{|c|c|c|c|c|c|c|c|c|c|}
\hline \multirow[t]{2}{*}{ Study } & \multicolumn{4}{|c|}{ Selection } & \multirow{2}{*}{$\begin{array}{c}\text { Comparability } \\
\text { basis of the } \\
\text { design or analysis }\end{array}$} & \multirow{2}{*}{\multicolumn{2}{|c|}{$\begin{array}{c}\text { Outcome } \\
\text { follow-up } \\
\text { long enough } \\
\text { for outcomes }\end{array}$}} & \multirow[b]{2}{*}{$\begin{array}{l}\text { Adequate } \\
\text { follow up }\end{array}$} & \multirow[t]{2}{*}{ Total } \\
\hline & $\begin{array}{l}\text { Representativeness } \\
\text { of the exposed cohort }\end{array}$ & $\begin{array}{l}\text { Selection of the non } \\
\text { exposed cohort }\end{array}$ & $\begin{array}{c}\text { Ascertainment } \\
\text { of exposure }\end{array}$ & $\begin{array}{l}\text { Demonstration that } \\
\text { outcome of interest }\end{array}$ & & & & & \\
\hline Pisters, Ron [15] & 1 & 1 & 1 & 1 & 1 & 1 & 1 & 1 & 8 \\
\hline Okcun, B [16] & 1 & 1 & 1 & 1 & 1 & 1 & 1 & 1 & 8 \\
\hline Hayashi, Takekuni [13] & 1 & 1 & 1 & 1 & 1 & 1 & 1 & 1 & 8 \\
\hline $\mathrm{Gu}, \mathrm{J}[17]$ & 1 & 1 & 1 & 1 & 1 & 1 & 1 & 1 & 8 \\
\hline de Vos, C. B [19] & 1 & 1 & 1 & 1 & 1 & 1 & 1 & 1 & 8 \\
\hline Holmqvist, F [29] & 1 & 1 & 1 & 1 & 1 & 1 & 1 & 1 & 8 \\
\hline Vidal-Perez, R [24] & 1 & 1 & 1 & 1 & 1 & 1 & 1 & 1 & 8 \\
\hline
\end{tabular}

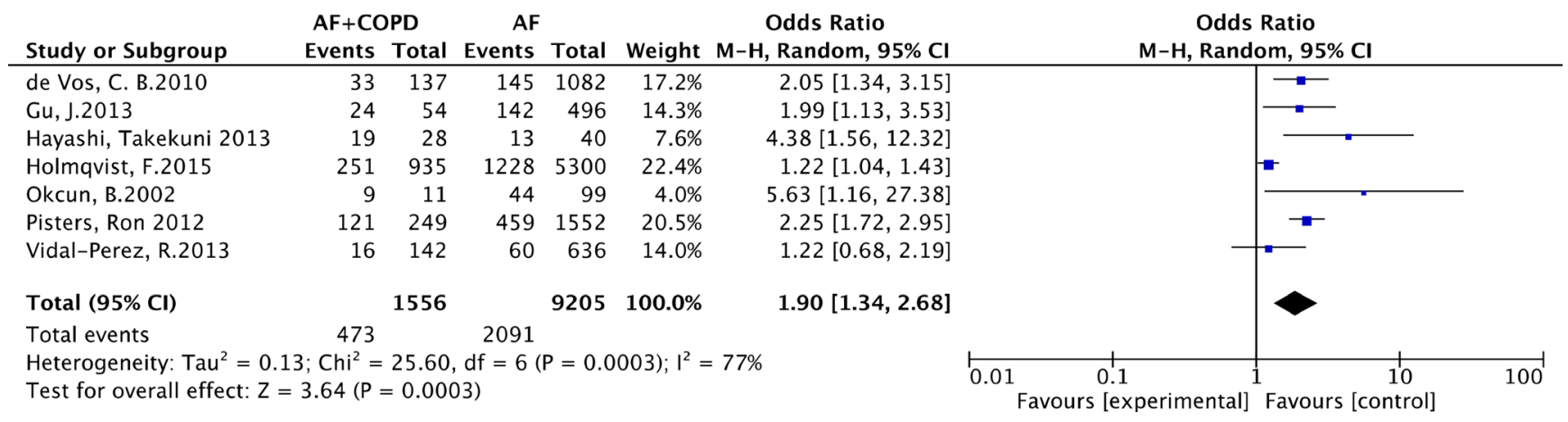

Figure 2: Forest plot on the association between COPD and atrial fibrillation recurrence and progression. 
COPD is also a vital risk factor for AF patients in terms major adverse cardiac events (MACE) including all-cause mortality, stroke, non-central nervous system systemic embolism and major bleed [25]. The cardiovascular and non-cardiovascular death were higher among AF patients with COPD [16]. However, there are no unanimous results about whether COPD could increase the risk of stroke or systemic embolism in AF patients. Some studies figured out that the presence of COPD might increase the occurrence of ischemic stroke in subjects with AF, while some other studies did not find $[26,27]$.

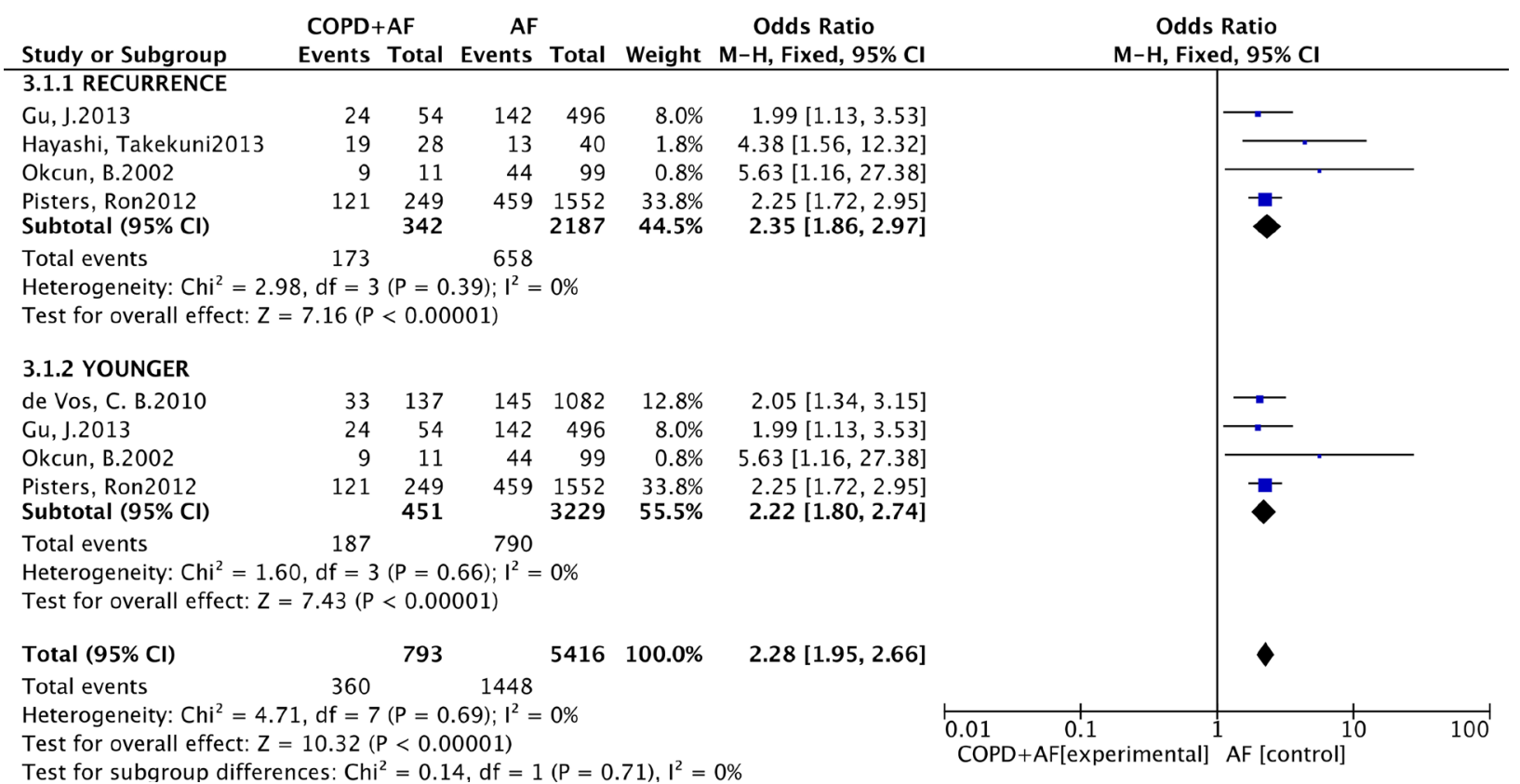

Figure 3: Subgroup analysis: forest plot on the association between COPD and atrial fibrillation recurrence.

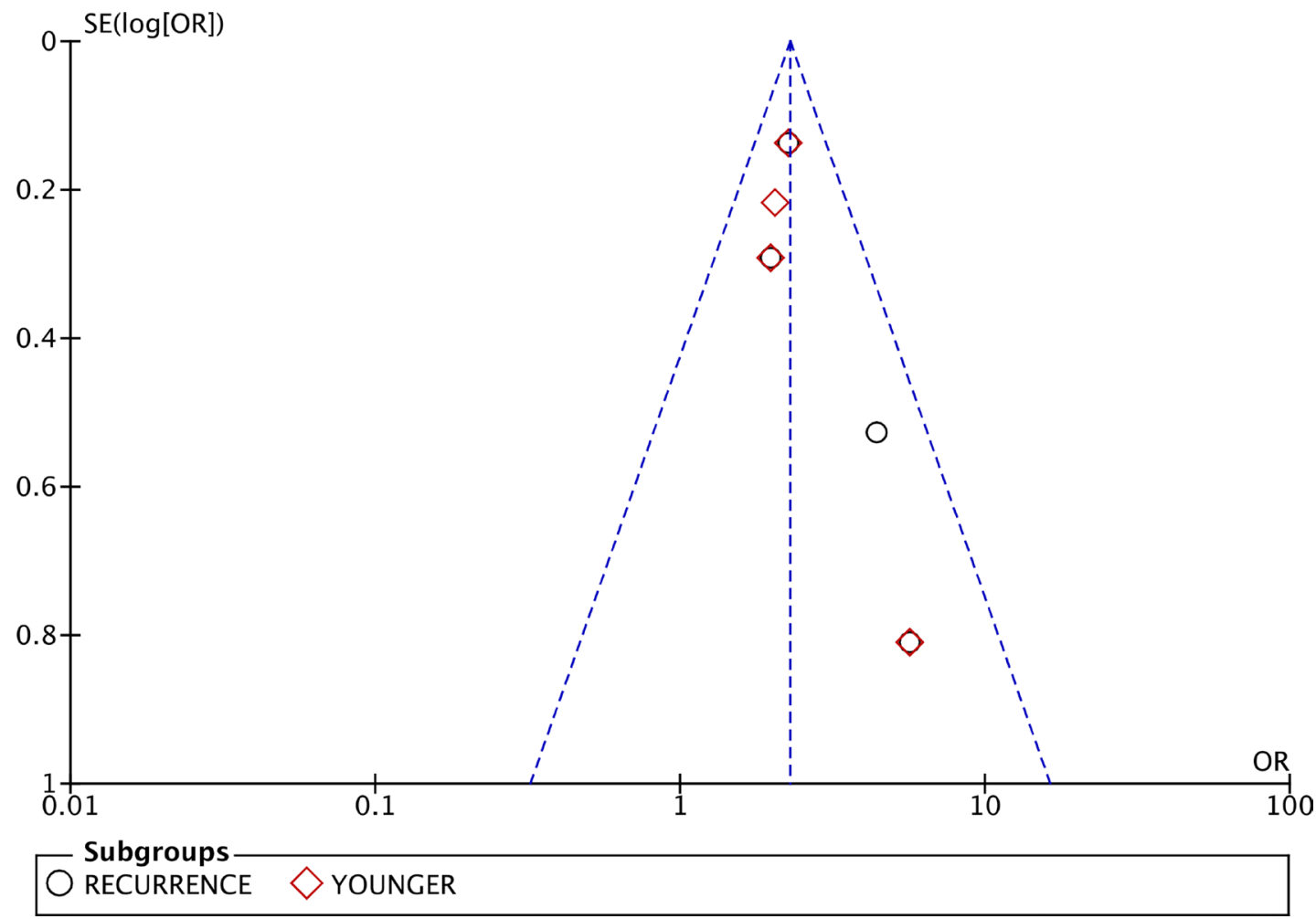

Figure 4: Funnel plot to analyze publication bias. 
Actually, long-term SR maintenance is an effective treatment to reduce the risk of complications related to $\mathrm{AF}$ and the reasonable control of ventricular rate can increase the survival rate [28]. Many patients with PAF included in this study progressed to persistent or permanent AF, despite hard effect to maintain sinus rhythm [19]. The absence of COPD is a predictor of the maintenance of sinus rhythm after electrical cardioversion or pharmacological cardioversion whether it is oral or intravenous chemical cardioversion [15]. Higher heart rates and advanced ages are also strong predictors for AF progression from paroxysmal or persistent a more sustained form $[29,30]$.

Catheter ablation of AF is widely applied for patients with symptomatic AF. COPD can affect lung morphological alterations which will cause marked change in PV anatomy, increasing the risk of AF recurrence. Non-pulmonary vein foci in the right atrial are also common in AF patients with COPD. The present study confirmed that catheter ablation of AF is feasible and safe in COPD patients using Bispectral index (BIS) monitoring to ablation [31].

Catheter ablation of AF can reduce AF progression risk [32]. Sometimes, prophylactic cavotricuspid isthmus ablation is needed to combine with PV isolation, which may be considered for patients with COPD. However, the recurrence of arrhythmia after first ablation is higher in this type of patients and most of them needed to be performed a second ablation [13, 33, 34].

Besides, AF will influence the drug treatment of COPD. Beta-adrenergic agonist and theophylline are usually used in the acute exacerbation of COPD, which can accelerate the ventricular rate in AF patients and might deteriorate the circulation stability. Salbutamol can increased heart rate, a strong predictor of AF progression [35]. The 2016 ESC guideline had clearly figured out that non-selective beta-blockers, propafenone and adenosine should be used with caution in patients with significant bronchospasm. Among AF patients with COPD beta-1 selective blockers like bisoprolol, metoprolol, are safe [36]. Amiodarone was the most widely used among all the antiarrhythmic drugs in the persist AF [37]. Antiarrhythmic drugs used as rhythm or rate control agents in the treatment of AF have been associated with a reduction in cardiovascular but not in all-cause mortality, which may seem reasonable considering their mode of action.

As for the predictor of the successful electrical cardioversion, the absence of COPD, chronic heart failure, obstructive sleep apnea syndrome (OSAS), valvular disease, higher HATCH scores, larger left atrial diameter, lower ejection fraction(EF) and advanced ages remained significant [17].

\section{CONCLUSIONS}

AF progression and recurrence in patients with COPD are of higher risks for mortality, stroke and
MACE. COPD is an independent risk for AF progression and recurrence. COPD patients with AF carry a worse prognosis than those in SR. Therefore, to maintain SR long-term may help to reduce the negative impact of AF in COPD patients with effective rhythm control treatments.

\section{Limitations}

This study presents the following limitations. First, the present studies include all the treatment of AF including the catheter ablation, electrical cardioversion and drug cardioversion to evaluate the outcome. However, the choose of therapy is based on the overall evaluation of the patients' physical condition and most of the medicationrefractory AF will undergo catheter ablation, which might cause selection bias. Additionally, most patients are not only combined with COPD. Patients with AF and COPD have more traditional cardiovascular risk factors (diabetes mellitus, hypertension, aging, heart failure, impaired renal function, obesity, larger LA diameter), all of which are important parameters that predict recurrence and progression. These complicated clinical features may weaken the predictive effects of comorbidity COPD on progression and recurrence. Thirdly, in order to include the largest dates, almost all of them are observed studies and prospective studies instead of random control trials. There might be some selection bias.

\section{ACKNOWLEDGMENTS AND FUNDING}

The authors are indebted to all the donors whose names were not included in the author list, but who participated in our study. This work was supported by National Natural Science Foundation of China [81270382].

\section{CONFLICTS OF INTEREST}

The authors declare that they have no conflicts of interest with this study.

\section{REFERENCES}

1. Potpara TS, Stankovic GR, Beleslin BD, Polovina MM, Marinkovic JM, Ostojic MC, Lip GY. A 12-year followup study of patients with newly diagnosed lone atrial fibrillation: implications of arrhythmia progression on prognosis: the Belgrade Atrial Fibrillation study. Chest. 2012; 141:339-47. https://doi.org/10.1378/chest.11-0340.

2. Tischer TS, Schneider R, Lauschke J, Diedrich D, Kundt G, Bansch D. Prevalence of atrial fibrillation and the HATCH score: Intensified monitoring of patients with high $\mathrm{HATCH}$ score. Herz. 2015; 40:803-8. https://doi.org/10.1007/ s00059-015-4305-4.

3. Yang YM, Shao XH, Zhu J, Zhang H, Liu Y, Gao X, Liu LS, Yu LT, Zhao L, Yu PF, Zhang H, He Q, Gu XD. Risk 
factors and incidence of stroke and MACE in Chinese atrial fibrillation patients presenting to emergency departments: a national wide database analysis. Int J Cardiol. 2014; 173:242-7. https://doi.org/10.1016/j.ijcard.2014.02.040.

4. Holford FD, Mithoefer JC. Cardiac arrhythmias in hospitalized patients with chronic obstructive pulmonary disease. Am Rev Respir Dis. 1973; 108:879-85. https://doi. org/10.1164/arrd.1973.108.4.879.

5. Shibata Y, Watanabe T, Osaka D, Abe S, Inoue S, Tokairin Y, Igarashi A, Yamauchi K, Kimura T, Kishi H, Aida Y, Nunomiya $\mathrm{K}$, Nemoto $\mathrm{T}$, et al. Impairment of pulmonary function is an independent risk factor for atrial fibrillation: the Takahata study. Int J Med Sci. 2011; 8:514-22.

6. Li J, Agarwal SK, Alonso A, Blecker S, Chamberlain AM, London SJ, Loehr LR, McNeill AM, Poole C, Soliman EZ, Heiss G. Airflow obstruction, lung function, and incidence of atrial fibrillation: the Atherosclerosis Risk in Communities (ARIC) study. Circulation. 2014; 129:971-80. https://doi.org/10.1161/circulationaha.113.004050.

7. Buch P, Friberg J, Scharling H, Lange P, Prescott E. Reduced lung function and risk of atrial fibrillation in the Copenhagen City Heart Study. Eur Respir J. 2003; 21:1012-6.

8. Andersson T, Magnuson A, Bryngelsson IL, Frobert O, Henriksson KM, Edvardsson N, Poci D. All-cause mortality in 272,186 patients hospitalized with incident atrial fibrillation 1995-2008: a Swedish nationwide long-term case-control study. Eur Heart J. 2013; 34:1061-7. https:// doi.org/10.1093/eurheartj/ehs469.

9. Zhang L, Huang B, Scherlag BJ, Ritchey JW, Embi AA, Hu J, Hou Y, Po SS. Structural changes in the progression of atrial fibrillation: potential role of glycogen and fibrosis as perpetuating factors. Int J Clin Exp Pathol. 2015; 8:1712-8.

10. Ogi H, Nakano Y, Niida S, Dote K, Hirai Y, Suenari K, Tonouchi Y, Oda N, Makita Y, Ueda S, Kajihara K, Imai K, Sueda $\mathrm{T}$, et al. Is structural remodeling of fibrillated atria the consequence of tissue hypoxia? Circ J. 2010; 74:1815-21.

11. Terzano C, Romani S, Conti V, Paone G, Oriolo F, Vitarelli A. Atrial fibrillation in the acute, hypercapnic exacerbations of COPD. Eur Rev Med Pharmacol Sci. 2014; 18:2908-17.

12. Krijthe BP, Heeringa J, Kors JA, Hofman A, Franco OH, Witteman JC, Stricker BH. Serum potassium levels and the risk of atrial fibrillation: the Rotterdam Study. Int J Cardiol. 2013; 168:5411-5. https://doi.org/10.1016/j.ijcard.2013.08.048.

13. Hayashi T, Fukamizu S, Hojo R, Komiyama K, Tanabe Y, Tejima T, Nishizaki M, Hiraoka M, Ako J, Momomura S, Sakurada H. Prevalence and electrophysiological characteristics of typical atrial flutter in patients with atrial fibrillation and chronic obstructive pulmonary disease. Europace. 2013; 15:1777-83. https://doi.org/10.1093/ europace/eut158.

14. Liao JN, Chao TF, Liu CJ, Wang KL, Chen SJ, Lin YJ, Chang SL, Lo LW, Hu YF, Tuan TC, Chung FP, Chen TJ, Chen SA. Incidence and risk factors for new-onset atrial fibrillation among patients with end-stage renal disease undergoing renal replacement therapy. Kidney Int. 2015; 87:1209-15. https://doi.org/10.1038/ki.2014.393.

15. Pisters R, Nieuwlaat R, Prins MH, Le Heuzey JY, Maggioni AP, Camm AJ, Crijns HJ; Euro Heart Survey Investigators. Clinical correlates of immediate success and outcome at 1-year follow-up of real-world cardioversion of atrial fibrillation: the Euro Heart Survey. Europace. 2012; 14:666-74. https://doi.org/10.1093/europace/eur406.

16. Okcun B, Yigit Z, Kucukoglu MS, Mutlu H, Sansoy V, Guzelsoy D, Uner S. Predictors for maintenance of sinus rhythm after cardioversion in patients with nonvalvular atrial fibrillation. Echocardiography. 2002; 19:351-7.

17. Gu J, Liu X, Tan H, Zhou L, Jiang W, Wang Y, Liu Y, Gu J. Impact of chronic obstructive pulmonary disease on procedural outcomes and quality of life in patients with atrial fibrillation undergoing catheter ablation. J Cardiovasc Electrophysiol. 2013; 24:148-54. https://doi.org/10.1111/ j.1540-8167.2012.02448.x.

18. Keating RJ, Gersh BJ, Hodge DO, Weivoda PL, Patel PJ, Hammill SC, Shen WK. Effect of atrial fibrillation pattern on survival in a community-based cohort. The American journal of cardiology. 2005; 96:1420-4. https://doi. org/10.1016/j.amjcard.2005.07.050.

19. de Vos CB, Pisters R, Nieuwlaat R, Prins MH, Tieleman RG, Coelen RJ, van den Heijkant AC, Allessie MA, Crijns HJ. Progression from paroxysmal to persistent atrial fibrillation clinical correlates and prognosis. J Am Coll Cardiol. 2010; 55:725-31. https://doi.org/10.1016/j.jacc.2009.11.040.

20. Pokorney SD, Piccini JP, Stevens SR, Patel MR, Pieper KS, Halperin JL, Breithardt G, Singer DE, Hankey GJ, Hacke W, Becker RC, Berkowitz SD, Nessel CC, et al. Cause of Death and Predictors of All-Cause Mortality in Anticoagulated Patients With Nonvalvular Atrial Fibrillation: Data From ROCKET AF. J Am Heart Assoc. 2016; 5:e002197. https:// doi.org/10.1161/jaha.115.002197.

21. Lip GY, Laroche C, Ioachim PM, Rasmussen LH, VitaliSerdoz L, Petrescu L, Darabantiu D, Crijns HJ, Kirchhof P, Vardas P, Tavazzi L, Maggioni AP, Boriani G. Prognosis and treatment of atrial fibrillation patients by European cardiologists: one year follow-up of the EURObservational Research Programme-Atrial Fibrillation General Registry Pilot Phase (EORP-AF Pilot registry). Eur Heart J. 2014; 35:3365-76. https://doi.org/10.1093/eurheartj/ehu374.

22. Huang B, Yang Y, Zhu J, Liang Y, Zhang H, Tian L, Shao X, Wang J. Clinical characteristics and prognostic significance of chronic obstructive pulmonary disease in patients with atrial fibrillation: results from a multicenter atrial fibrillation registry study. J Am Med Dir Assoc. 2014; 15:576-81. https://doi.org/10.1016/j.jamda.2014.04.009.

23. Bjorck F, Renlund H, Svensson PJ, Sjalander A. Warfarin persistence among stroke patients with atrial fibrillation. Thromb Res. 2015; 136:744-8. https://doi.org/10.1016/j. thromres.2015.07.028.

24. Vidal-Perez R, Otero-Ravina F, Lado-Lopez M, TurradoTurrado V, Rodriguez-Moldes E, Gomez-Vazquez JL, de 
Frutos-de Marcos C, de Blas-Abad P, Besada-Gesto R, Gonzalez-Juanatey JR. The change in the atrial fibrillation type as a prognosis marker in a community study: long-term data from AFBAR (Atrial Fibrillation in the BARbanza) study. Int J Cardiol. 2013; 168:2146-52. https://doi. org/10.1016/j.ijcard.2013.01.261.

25. Wang J, Yang YM, Zhu J, Zhang H, Shao XH, Huang B, Tian L. Analysis of risk factors for all cause-mortality in Chinese emergency atrial fibrillation patients. [Article in Chinese]. Zhonghua Yi Xue Za Zhi. 2013; 93:2871-5.

26. Nadeem R, Sharieff A, Tanna S, Sidhu H, Molnar J, Nadeem A. Potential Augmentation of the Risk of Ischemic Cerebrovascular Accident by Chronic Obstructive Pulmonary Disease in Patients with Atrial Fibrillation. J Stroke Cerebrovasc Dis. 2015; 24:1893-6. https://doi. org/10.1016/j.jstrokecerebrovasdis.2015.04.034.

27. Durheim MT, Cyr DD, Lopes RD, Thomas LE, Tsuang WM, Gersh BJ, Held C, Wallentin L, Granger CB, Palmer SM, Al-Khatib SM. Chronic obstructive pulmonary disease in patients with atrial fibrillation: Insights from the ARISTOTLE trial. Int J Cardiol. 2016; 202:589-94. https:// doi.org/10.1016/j.ijcard.2015.09.062.

28. Wan H, Yang Y, Zhu J, Shao X, Wang J, Huang B, Zhang $H$. The prognostic effects of ventricular heart rate among patients with permanent atrial fibrillation with and without coronary artery disease: a multicenter prospective observational study. Medicine (Baltimore). 2015; 94:e920. https://doi.org/10.1097/md.0000000000000920.

29. Holmqvist F, Kim S, Steinberg BA, Reiffel JA, Mahaffey KW, Gersh BJ, Fonarow GC, Naccarelli GV, Chang P, Freeman JV, Kowey PR, Thomas L, Peterson ED, et al. Heart rate is associated with progression of atrial fibrillation, independent of rhythm. Heart. 2015; 101:894-9. https://doi.org/10.1136/heartjnl-2014-307043.

30. Shao XH, Yang YM, Zhu J, Zhang H, Liu Y, Gao X, Yu LT, Liu LS, Zhao L, Yu PF, Zhang H, He Q, Gu XD. Comparison of the clinical features and outcomes in two age-groups of elderly patients with atrial fibrillation. Clin Interv Aging. 2014; 9:1335-42. https://doi.org/10.2147/cia. s67123.

31. Roh SY, Choi JI, Lee JY, Kwak JJ, Park JS, Kim JB, Lim HE, Kim YH. Catheter ablation of atrial fibrillation in patients with chronic lung disease. Circ Arrhythm Electrophysiol. 2011; 4:815-22. https://doi.org/10.1161/ circep.110.960435.
32. Jongnarangsin K, Suwanagool A, Chugh A, Crawford T, Good E, Pelosi F Jr, Bogun F, Oral H, Morady F. Effect of catheter ablation on progression of paroxysmal atrial fibrillation. J Cardiovasc Electrophysiol. 2012; 23:9-14. https://doi.org/10.1111/j.1540-8167.2011.02137.x.

33. Perez-Rodon J, Rodriguez-Garcia J, Sarrias-Merce A, Rivas-Gandara N, Roca-Luque I, Francisco-Pascual J, Santos-Ortega A, Martin-Sanchez G, Ferreira-Gonzalez I, Rodriguez-Palomares J, Evangelista-Masip A, Garcia-Dorado D, Moya-Mitjans A. Predictors of acute inefficacy and the radiofrequency energy time required for cavotricuspid isthmus-dependent atrial flutter ablation. J Interv Card Electrophysiol. 2017; 49:83-91. https://doi. org/10.1007/s10840-017-0232-z.

34. Seara JG, Roubin SR, Gude Sampedro F, Barreiro VB, Sande JM, Manero MR, Grandio PC, Alvarez B, Juanatey JG. Risk of atrial fibrillation, stroke, and death after radiofrequency catheter ablation of typical atrial flutter. Clin Res Cardiol. 2014; 103:543-52. https://doi.org/10.1007/ s00392-014-0682-6.

35. Banasiak W, Telichowski C, Molenda W. Effect of salbutamol on heart rate in patients with atrial fibrillation. [Article in Polish]. Pol Arch Med Wewn. 1992; 87:77-82.

36. Kirchhof P, Benussi S, Kotecha D, Ahlsson A, Atar D, Casadei B, Castella M, Diener HC, Heidbuchel H, Hendriks J, Hindricks G, Manolis AS, Oldgren J, et al. 2016 ESC Guidelines for the Management of Atrial Fibrillation Developed in Collaboration With EACTS. Rev Esp Cardiol (Engl Ed). 2017; 70:50. https://doi.org/10.1016/j. rec.2016.11.033.

37. Vinolas X, Freire F, Romero-Menor C, Alegret JM. Predictors of reversion to sinus rhythm previous to electrical cardioversion in patients with persistent atrial fibrillation treated with anti-arrhythmic drugs. [Article in Spanish]. Med Clin (Barc). 2013; 140:351-5. https://doi. org/10.1016/j.medcli.2012.02.026. 